\title{
Network Perspective on the Efficiency of Peace Accords Implementation
}

\author{
Henry K. Dambanemuya* \\ Madhav Joshi \\ Emőke-Ágnes Horvát \\ Department of Communication Studies Kroc Institute for International Peace Studies Department of Communication Studies \\ Northwestern University \\ Evanston, USA \\ University of Notre Dame \\ Notre Dame, USA \\ Northwestern University \\ Evanston, USA \\ hdambane@u.northwestern.edu \\ mjoshi2@nd.edu \\ a-horvat@northwestern.edu
}

\begin{abstract}
Civil wars are as frequent and debilitating now as ever. More often than not, their resolution consists of the negotiation of a peace accord that involves a number of provisions. Although previous work in political science indicates an underlying interdependence between provision implementation sequences, it is unclear how the structure and dynamics of this interdependence relate to the successful implementation of peace accords. To fill this gap, we systematically study peace process implementation activity from 34 peace accords containing 51 provisions negotiated between 1989 and 2015. We begin by constructing a bipartite network between peace accords and their provisions' implementation and explore statistical properties of the structural underpinnings of peace processes. Then, we examine motifs (i.e., significantly frequent patterns) in provision implementation activity and uncover higher order correlations between provisions. Finally, we identify provision implementation sequences (i.e., meta-groups) that are most strongly associated with successful peace processes. Our empirical findings provide new insights for the implementation of peace accords by revealing temporal sequences of peace process implementation that help build confidence, enhance security, and ultimately prevent negative cascading effects in different stages of the peacebuilding process.
\end{abstract}

Index Terms-Bipartite Networks, Motifs, Meta-Groups, Topological Sorting, Peacebuilding

\section{INTRODUCTION}

The historical pattern of civil war termination indicates that, over the past 30 years, negotiated peace settlements have surpassed battle victories to become the predominant way of ending civil wars [1] -[3]. In fact, between 1989 and 2015, 69\% of 142 civil war terminations were peacefully negotiated [4]. Once a peace settlement is reached, a number of implementation sequences are possible to put the negotiated provisions

The authors would like to thank Orsolya Vaśaŕhelyi, Kyosuke Tanaka, Igor Zakhlebin, and Nicholas Hagar for their feedback. This work was partially funded by the U.S. National Science Foundation under Grant No. IIS-1755873.

* Corresponding author.

Permission to make digital or hard copies of all or part of this work for personal or classroom use is granted without fee provided that copies are not made or distributed for profit or commercial advantage and that copies bear this notice and the full citation on the first page. Copyrights for components of this work owned by others than ACM must be honored. Abstracting with credit is permitted. To copy otherwise, or republish, to post on servers or to redistribute to lists, requires prior specific permission and/or a fee. Request permissions from permissions@acm.org

ASONAM '19, August 27-30, 2019, Vancouver, Canada

(C) 2019 Association for Computing Machinery.

ACM ISBN 978-1-4503-6868-1/19/08/\$15.00

http://dx.doi.org/10.1145/3341161.3342895 into practice. However, determining which provision structure and implementation sequence is most likely to result in a successful implementation remains a difficult task [5]. Consequently, negotiated peace settlements often last 3.5 years before conflict resumes, risking a $23 \%$ chance of conflict reversion during the initial 5 years of implementation and $17 \%$ chance of reversion in the subsequent 5 years [6], [7]. From a systems perspective, the connections between peace accords and their provision implementation represent a par excellence complex network with intriguing topological features. The network encodes social, economic, and political phenomena resulting in interdependencies that make it difficult to predict how a peace process will unfold by simply examining the individual provisions negotiated in a settlement.

As a pioneering effort in researching peace accords from a network perspective, this study investigates the evolution of peace accords together with the implementation of their provisions. This enables us to uncover how different subgraphs and sequences in implementation activity lead to different peace process outcomes. We begin by constructing and statistically characterising the bipartite network between peace accords and the provisions they negotiated. We adapt network measures to systematically describe the association between peace accords and their provisions. These measures quantify the diversification of peace accords in terms of the provisions they negotiate, the ubiquity of provisions in unique peace accords, and the implementability of provisions as measured by the extent to which each provision is implemented across all peace accords that contain it. To further explore the underlying patterns in peace process implementation, we identify network motifs (i.e., recurring, statistically significant implementation sub-graphs) and meta-groups (i.e., directed implementation sequences) that are associated with successful implementations. We compare motifs characteristic among peace processes with high and low implementation success. Finally, our meta-group analysis uses a topological sorting algorithm for determining the precedence of provisions and reveals critical paths or implementation sequences that are more likely to lead to successful peace process implementation.

To the best of our knowledge, this is the first study to investigate the structural interdependencies underlying peace process dynamics using approaches and tools from social 


\section{IEEE/ACM International Conference on Advances in Social Networks Analysis and Mining}

network analysis and aiming for a better understanding of factors that drive peace process outcomes. The paper's specific contributions are threefold:

1) It adopts a set of network measures to provide a comprehensive characterisation of peace accords implementation in terms of diversity, ubiquity, and implementability.

2) It detects statistically significant patterns among peace processes with low and high implementation success using an appropriate ensemble of degree-preserving randomised bipartite networks.

3) It identifies directed chronological implementation sequences that are characteristic of high and low implementation success, demonstrating the untapped potential of network methods to detect the subtle structural and habitual forces that often make peacebuilding difficult.

Our study contributes thus new knowledge to the body of literature on civil war termination and peacebuilding by providing new empirical findings for peace research using complex network analysis.

The remainder of the paper is structured as follows: We begin by identifying literature on relevant network methods (i.e., measures of bipartite networks, motifs, and meta-groups) deployed previously in a variety of domains but peacebuilding. We then briefly survey existing peace research that demonstrates the salience of interdependencies in implementation activity and sequencing. Next, we describe the data used in this study and present new network measures for characterising the association between peace accords and their provisions. Following these explorations, we describe the methods employed for motif detection and meta-group analysis, present analysis results, and discuss the implications of our study for peacebuilding practice.

\section{RELATED WORK}

Although network studies investigating peace process implementation are largely missing, we find literature on network models of broadly construed international relations. After surveying a few exemplary papers from this wide area, we briefly mention qualitative studies on peacebuilding that informed the questions we address in this paper and then review a set of network analytic papers that inspired the selection of network methods that we use.

Several applications of network science exist in a variety of peacebuilding-related disciplines. For example, Doreian et al. utilised signed blockmodeling to study the multifaceted dynamics of international relations [8]. Hafner et al. illustrate how network analysis can serve as a toolkit to deepen existing research on key international outcomes and as an instrument for testing existing theories [9]. Despite these advances in a variety of related disciplines, network research on critical challenges to and inter-linkages of peace processes is scarce. For the most part, existing scholarship on peace accords implementation is of qualitative nature [5], [10]-[13], with the exception of Maekawa et al. who employed a linear regression model to examine the effect of peacekeeping deployment on the rate of peace accords implementation [14]. The authors found evidence that third-party guarantees such as the presence of UN Peacekeeping Missions increase the overall likelihood that peace accords will be implemented. Once implementation has begun, Joshi et al. found that the level of peace accords implementation is a significant predictor for durable peace [15]. The same authors further demonstrate that the sequencing of provision implementation can reduce destabilising effects of post-accord elections, granted that pre-election accommodation measures have been implemented [16].

The complex relationships between peace accords and provisions lend themselves to modelling with two-mode or bipartite networks. Bipartite networks are popular for studying interactions in several domains [17] including human collaboration in the entertainment industry [18] and knowledge production [19], in ecological [20], [21] and human [20] communities, and in bio-geography [22], [23], finance [24], and trade $[25]-[28]$. Despite the prevalence of bipartite networks in complex systems studies, their properties are difficult to study using standard network measures such as average path length and clustering coefficient due to their two-mode nature. For example, the usual clustering coefficient measure of uni-modal networks cannot be defined for bipartite networks where no odd cycles of any length can be observed, because links between the same type of nodes are forbidden. Previous studies on bipartite networks therefore typically rely on measures of degree (the number of connections a node has) and strength (the sum of weights for edges that are adjacent to the node), nestedness (the extent to which nodes with few connections are indirectly interacting with nodes that have many connections), and connectance (the proportion of possible connections observed). Furthermore, higher order correlations between nodes can be defined through motifs. Motif analysis is well-established in the study of unipartite networks [29] and budding in the context of bipartite networks. Research on ecological and economic networks has shown that bipartite motifs are common in biological systems for studying widespread nestedness in mutualistic communities [30], [31] as well as in non-biological systems for studying trade patterns [28] and assessing similarities in stock market portfolios [24]. Another strand of research that is highly relevant to our study developed network meta-groups to investigate event sequences in dynamic bipartite networks [32].

Our work builds upon these existing studies to merge network methods and relevant problems in peacebuilding, eventually advancing both of those areas.

\section{DATA}

We rely on data from the Peace Accords Matrix (PAM) [33], the largest existing collection of implementation data on intrastate peace accords. The data set comprises 51 provisions contained in 34 Comprehensive Peace Accords (CPA) negotiated between 1989 and 2015. The peace accords are comprehensive because (a) the major parties to the conflict were involved in the negotiations that produced the peace accord; and (b) the substantive issues underlying the dispute were included in the negotiations [34]. Peace accords that 


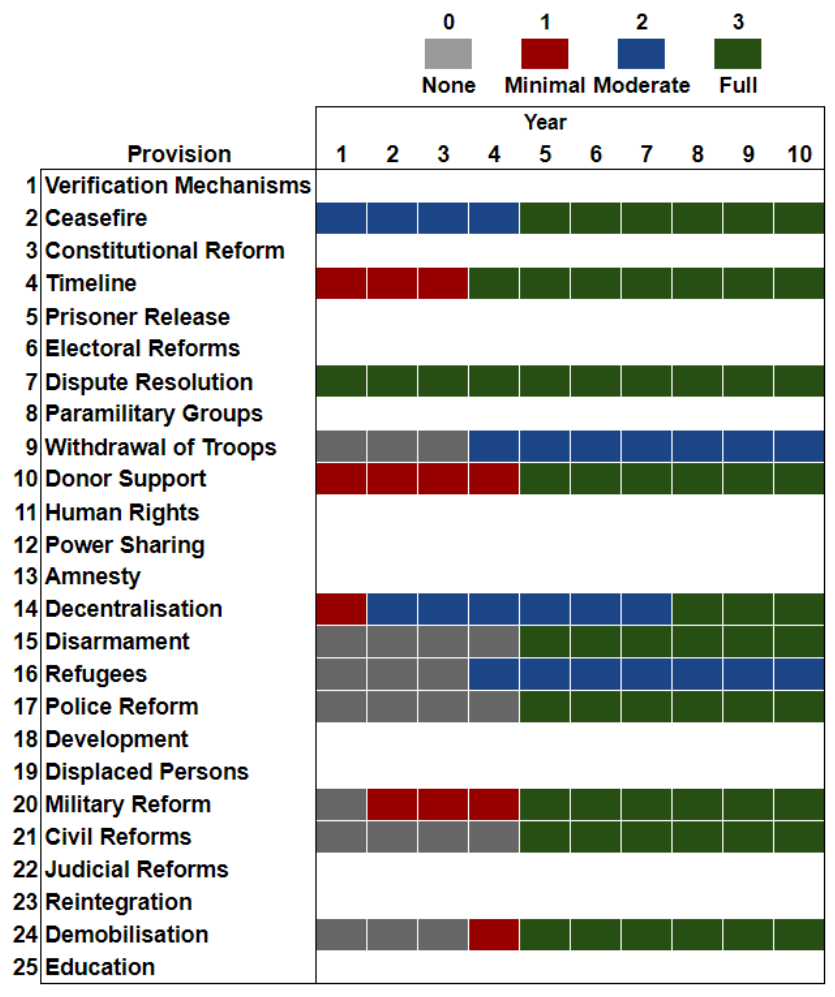

Fig. 1: Provision implementation levels during the first decade after the signing of the Mali National Pact in June 1991. Shown are the 25 provisions that occur most frequently across the data set.

fail to meet either of these two criteria are excluded from the database. A major party is one that has sufficient mobilisation capacity and influence to alter the outcome of a peace process [35]. A provision is a legal clause or condition contained within a contract that requires one or more parties to fulfil a particular responsibility within a specified period of time. The data measures the implementation points of each provision in the decade following the signing of the accord using four ordinal categories: $0=$ no, $1=$ minimal, $2=$ moderate, and $3=$ full implementation. The provisions are further grouped into six categories: ceasefire, institutions, security, rights, external arrangements, and other topics. The 10-year update captures both progress in terms of the implementation of the provisions of the peace accords as well as any setbacks and implementation reversal. Figure 1 shows as an example the implementation of the Mali National Pact signed in 1991, listing the 25 provisions that occur most frequently in our data. For each peace accord, we thus know the total implementation points as the sum of implementation points of all provisions in the peace accord as well as the aggregate implementation score as the ratio of total implementation points to the peace accord's highest possible implementation score (number of provisions*3). This yields a normalised annual percentage. In the example of the Mali National Pact, the total implementation points are 40 , while the aggregate implementation score is $83.33 \%$.

\section{NeTwork Properties}

We rely on the PAM data described above to construct a bipartite graph, $G=(A, P, E)$, consisting of two disjoint and independent sets of nodes, accords $(A)$ and provisions $(P)$, such that each edge, $E$, includes a member of $A$ and a member of $P$. We use the bi-adjacency matrix, $\mathbf{M}=G$, to represent the data. We rely on binary and weighted networks to describe the negotiation and implementation relationships between the nodes, respectively. The binary network describes the relation $m_{a p}=1$ that connects the nodes when a peace accord negotiates a provision and $m_{a p}=0$, otherwise. From the binary network, we compute the basic network properties shown in Table I. Accordingly, $41.75 \%$ percent of the maximally possible connections are present in the binary network, which indicates that peace accords tend to contain a large number of provisions. This high connectance is due to the data only recording comprehensive peace accords.
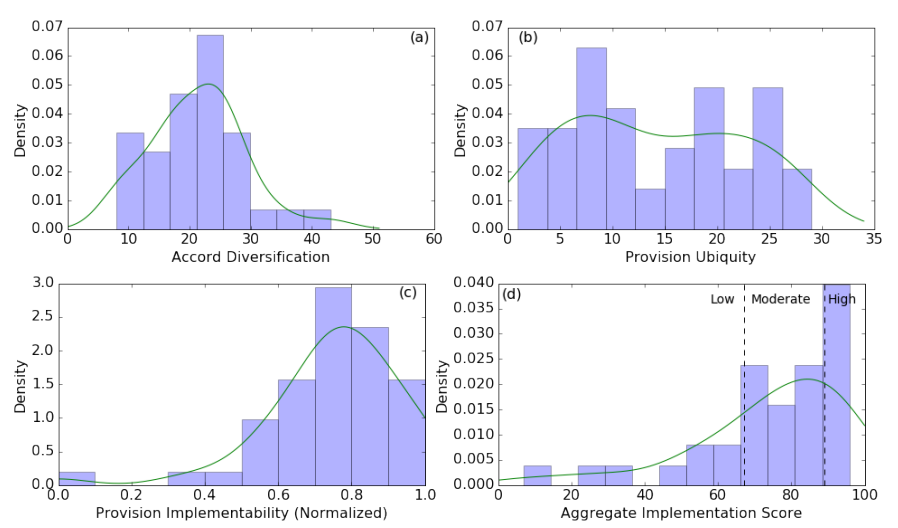

Fig. 2: Kernel density estimates of (a) accord diversification, (b) provision ubiquity, (c) normalized provision implementability, and (b) accord aggregate implementation score.

We proceed by investigating the degree distributions of peace accords and their provisions. Just like in research on economic networks [28], for peace accords, we establish an $a c$ cord diversification measure, $d_{a}(\mathbf{M})=\sum_{p=1}^{P} m_{a p}$, that represents the accord degree or number of unique provisions negotiated by a peace accord. The average accord diversification is 21 , meaning that, on average, $41.18 \%$ of all the provisions are negotiated in a peace accord (see Figure 2a). Additionally, we compute a provision ubiquity measure, $u_{p}(\mathbf{M})=\sum_{a=1}^{A} m_{a p}$, that represents the provision degree or number of unique peace accords that negotiate the provision. As shown in Figure $2 \mathrm{~b}$, the distribution of provision ubiquity is bi-modal, indicating that there are specialist and generalist provisions with the former being less and the latter being more frequently negotiated. Based on this measure, some examples of generalist provisions include those that are necessary for civil-war termination such as a ceasefire agreement to end hostilities as well as Disarmament, Demobilisation, and Re-integration (DDR) strategies for transitioning former combatants into civilian society. Specialist provisions include conflict-specific interventions such 


\section{IEEE/ACM International Conference on Advances in Social Networks Analysis and Mining}

TABLE I: Summary statistics for the complete binary bipartite network as well as the subnetworks with low, moderate, and high implementation.

\begin{tabular}{|l|l|l|l|l|l|}
\hline Measure & Formula & $\begin{array}{l}\text { Complete } \\
\text { Network }\end{array}$ & $\begin{array}{l}\text { Low } \\
\text { Implementation }\end{array}$ & $\begin{array}{l}\text { Moderate } \\
\text { Implementation }\end{array}$ & $\begin{array}{l}\text { High } \\
\text { Implementation }\end{array}$ \\
\hline Accords & $A$ & 34 & 9 & 16 & 9 \\
Provisions & $P$ & 51 & 41 & 50 & 49 \\
Links & $L(\mathbf{M})=\sum_{a=1}^{A} \sum_{p=1}^{P} m_{a p}$ & 724 & 159 & 374 & 191 \\
Connectance & $c(\mathbf{M})=\frac{L(\mathbf{M})}{A \cdot P}$ & 0.42 & 0.35 & 0.46 & 0.42 \\
Average Diversification & $\overline{d_{a}}(\mathbf{M})=\frac{L(\mathbf{M})}{A(}$ & 21.29 & 17.67 & 23.38 & 21.22 \\
Average Ubiquity & $\overline{u_{p}}(\mathbf{M})=\frac{L(\mathbf{M})}{P}$ & 14.20 & 3.88 & 7.48 & 3.90 \\
Nestedness & see Equations 1 & 0.62 & 0.54 & 0.71 & 0.55 \\
\hline
\end{tabular}

as developing methods for resolving disagreements between disputants through third-party involvement as well as forming special committees to address damages and losses reported by victims of conflict.

To characterise the generalist-specialist balance in the observed network, we use a measure of nestedness that is widely employed in ecology to investigate species distribution among sites (e.g. islands, hosts, and resource patches). Similarly, this measure allows us to investigate the distribution of provisions among peace accords across the generalist-specialist spectrum. Specifically, we use Almeida-Neto et al's [36] measure of Nestedness based on Overlap and Decreasing Fill (NODF). We begin by defining:

$$
S_{a a^{\prime}}= \begin{cases}d_{a} \neq d_{a^{\prime}} & \frac{\sum_{p} m_{a p} m_{a^{\prime} p}}{\min \left\{d_{a}, d_{a^{\prime}}\right\}} \\ \text { otherwise } & 0\end{cases}
$$

where $S_{a a^{\prime}}$ are determined by the pairs of peace accords for which the number of ones in rows $a$ and $a^{\prime}$ are different. Next, we define:

$$
T_{p p^{\prime}}= \begin{cases}u_{p} \neq u_{p^{\prime}} & \frac{\sum_{a} m_{a p} m_{a p^{\prime}}}{\min \left\{u_{p}, u_{p^{\prime}}\right\}} \\ \text { otherwise } & 0\end{cases}
$$

where $T_{p p^{\prime}}$ are determined by the pairs of provisions for which the number of ones in columns $p$ and $p^{\prime}$ are different. Finally, NODF is defined as:

$$
N O D F=2 \frac{\sum_{a<a^{\prime}} S_{a a^{\prime}}+\sum_{p<p^{\prime}} T_{p p^{\prime}}}{A(A-1)+P(P-1)}
$$

which calculates a measure of nestedness among all provisions and peace accords by simply averaging all paired values of $A(A-1)$ rows and $P(P-1)$ columns. Accordingly, the binary network is nested when peace accords with low diversification have a subset of the most ubiquitous provisions. The index ranges from 0 to 1 where a value of 1 indicates perfect nesting. We observe a nestedness index of 0.623 .

The weighted network describes, quantitatively, the strength of the relation, $m_{a p}$, that specifies the extent to which an accord implements a provision. In the weighted network, we use the provision implementation level ranging from 0 to 3 on an ordinal scale, to measure the implementability of a provision, $n_{p}$, as the sum of the provision's implementation scores from all peace accords that implement it: $n_{p}(\mathbf{M})=\sum_{i=1}^{A} m_{a p}$. This measure represents the extent to which a provision is implemented by all peace accords that negotiated it and quantifies the ease of implementation and/or the cruciality of the provision (e.g., implementing a ceasefire agreement to end hostilities). Implementability is thus influenced by an incentive-compatible mechanism that leads to prioritising certain provisions over others. Since peace accords contain different numbers of provisions, we compute the normalised provision implementability, $\hat{n}_{p}(\mathbf{M})=\frac{n_{p}(\mathbf{M})}{\max \left\{n_{p}(\mathbf{M})\right\}}$, as a ratio of the observed provision implementability to its maximum possible, where: $\max \left\{n_{p}(\mathbf{M})\right\}=3 * d_{p}$. The resulting coefficient lies between 0 and 1 , where 1 indicates the highest provision implementability. Figure 2 e shows that the provision implementability follows a left-skewed normal distribution. The average of the normalised provision implementability is 0.751 (std $=0.185$ ), meaning that, on average, most provisions reach at least $75 \%$ aggregate implementation in the first decade after they are negotiated. The provisions with the highest normalised implementability $\left(\hat{n}_{p}=1\right.$ ) focus on external arrangements in facilitating the presence of a United Nations (UN) transitional authority and peacekeeping mission, international arbitration on issues such as land, rights to self-determination, independence referendum, and ratification mechanisms. These provisions are key to implementation success because belligerents often seek impartial international and internal verification of the peace process [33]. The provisions with the lowest normalised implementability $\left(\hat{n}_{p}<=0.5\right)$ pertain to media reforms, natural resource management, reparations, and the presence of a commission to address damages or loss. Similar to our findings, previous comparative analyses of the data demonstrate that belligerents are less likely to negotiate over these issues and where these provisions were negotiated, very few efforts were made to truly implement them [33].

\section{Motifs And Meta-Groups}

We proceed by examining underlying patterns in the frequency, concurrency, and sequence of implementation activity to identify (i) motifs: negotiation and implementation patterns that occur significantly more frequently in peace processes than by chance and (ii) meta-groups: directed implementation sequences deduced from node similarity and ordering. The focus of our study is to identify significant differences in network 


\section{IEEE/ACM International Conference on Advances in Social Networks Analysis and Mining}

motifs and meta-groups characteristic of high and low peace process implementation success. To establish a distinction between high, moderate, and low implementation peace accords, we divide them into three weighted bipartite networks based on the distribution of the aggregate implementation scores shown in Figure 2 $\mathrm{d}$. Low implementation networks comprise peace accords whose aggregate implementation score is within the lower-quartile range, whereas high implementation networks consist of peace accords with aggregate implementation score within the upper-quartile range. Peace accords whose aggregate implementation score falls within the inter-quartile range constitute moderate implementation networks. Table I provides a summary of each network's properties.

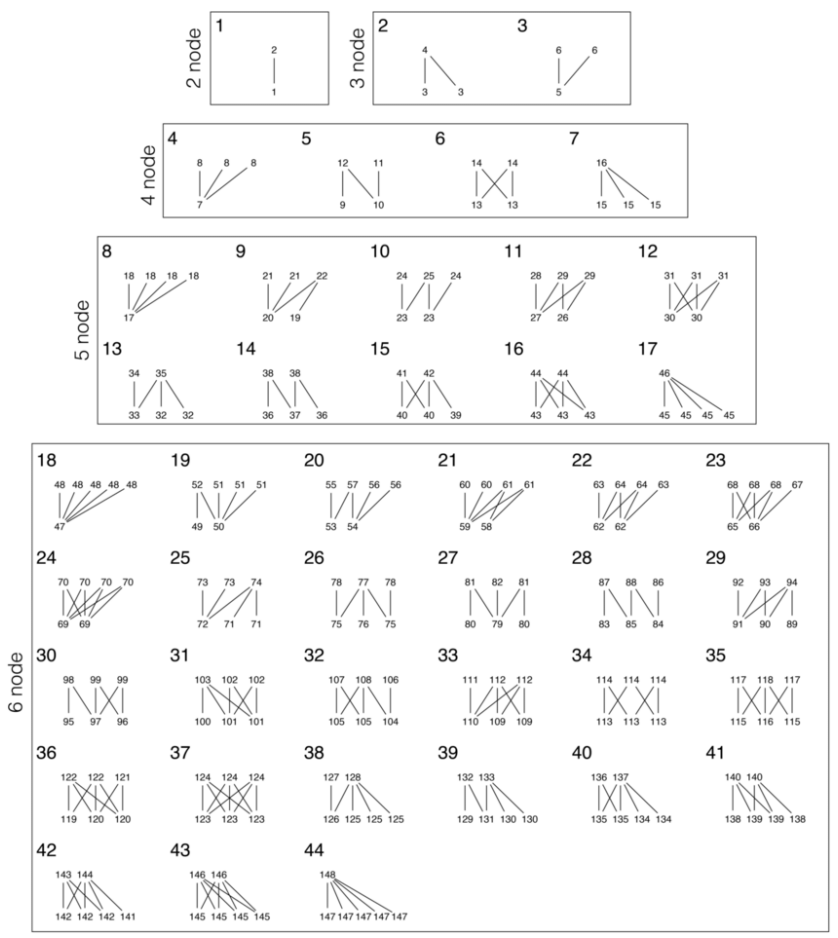

Fig. 3: All bipartite sub-graphs containing up to six nodes. Large numbers identify each sub-graph. Small numbers represent the unique positions nodes can occupy within sub-graphs. Source: [37].

\section{A. Higher Order Correlations in Implementation Activity}

Motifs have been introduced as the basic building blocks of networks [29]. Unlike aggregate network measures like degree and nestedness, motifs are significantly more sensitive to changes in network structure. Simmons et al., for example, found that bipartite motifs in ecological systems capture $63 \%$ more information about network structure compared to multivariate combinations of popular network-level indices [31]. Three features make bipartite motifs appealing for the study of peace processes: (1) Going beyond the level of dyads, they provide higher order correlations between groups of provisions and accords, enabling us to learn about implicit similarities in implementation; (2) They lend themselves to the separate study of low and high implementation peace processes, which is necessary for finding systematic differences between these two categories; and (3) Given the yearly resolution of our data, it is straightforward to compute motifs for different years, thereby uncovering aspects of the temporal evolution of implementation. For these reasons, we rely on motif analysis to investigate whether there exist specific recurring and statistically significant network signatures that differentiate high and low implementation success.

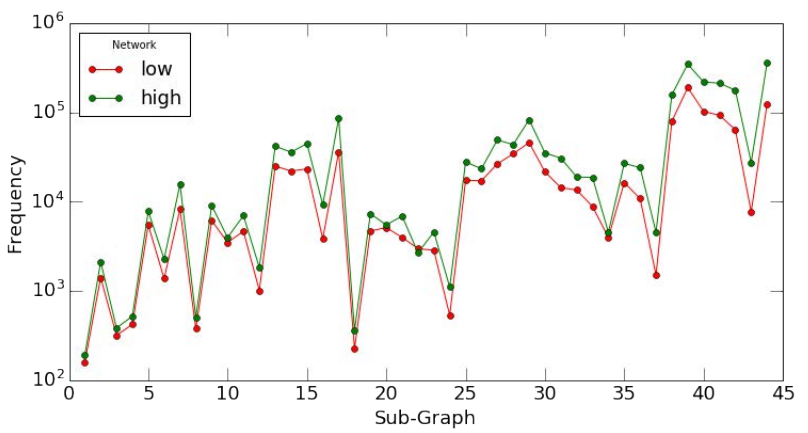

Fig. 4: The frequency with which each sub-graph shown in Figure 3 occurs in the static network connecting peace accords to negotiated provisions broken down by ultimate implementation success (low and high). There were no significant differences in frequencies between the two networks (KS test: $p=0.282$ ).

To perform this analysis, we compute efficiently the frequency of all 44 possible two- to six-node sub-graphs shown in Figure 3 using recently released software [37]. Within these 44 sub-graphs, individual nodes can occupy 148 unique positions, which represent different situations [31] and require appropriate counting. This detail ensures that observed patterns do not have a high significance simply because they have highly significant sub-patterns. To assess the statistical significance of these sub-graphs and thereby determine which ones are actual motifs, we construct a suitable ensemble of null networks that preserve network size, connectance, as well as the distributions of diversification and ubiquity - thereby enforcing a stringent comparison between the real network and the generated null networks. This way we account for the presence of sub-graphs that appear simply because of highly diversified accords and ubiquitous provisions. When building the ensemble, we use a Markov Chain Monte Carlo sampling method implemented via edge swaps [38]-[40]. Using this approach, we can identify motifs occurring at frequencies that are significantly higher than those in the randomised ensemble. Our ensemble contains 10,000 randomised networks, each created via 10,000 edge swaps. Motifs will be those sub-graphs for which the empirical probability $p$ of greater or equally appearance in a randomised network compared to the real network is less than a specified threshold. Alternatively, the significance of sub-graphs can be quantified using the $z$-score, which indicates how many standard deviations the observed sub-graph count is away from the expected count. Using both statistics, we obtain the same set of motifs and hereafter report only $z$-scores. 

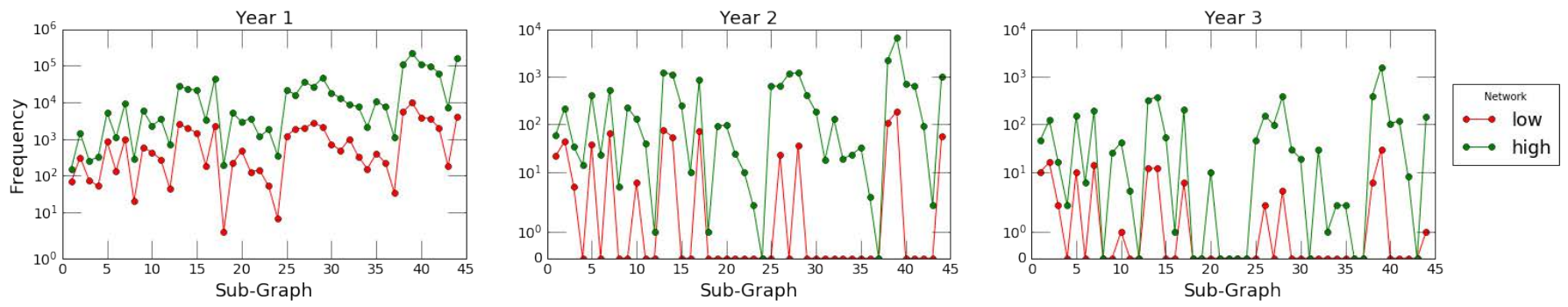

Fig. 5: The frequency with which each sub-graph shown in Figure 3 occurs in the networks deduced from implementation activity in the first three years. There exist notable differences in frequencies between low and high implementation networks.

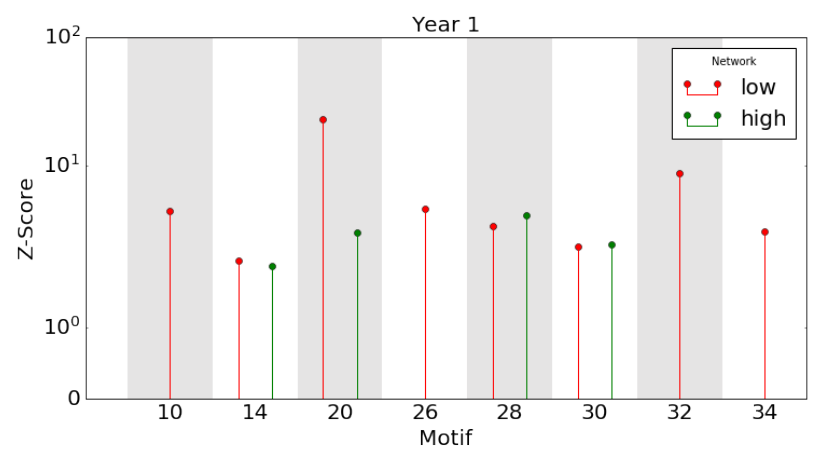

Fig. 6: Significance of motifs in low and high implementation networks.

Note that if we were to look at the static low vs high implementation networks between peace accords and their negotiated provisions, without regard to subsequent implementation activity, we would not find significant differences in terms of the frequencies of their sub-graphs as shown in Figure 4. This means that high and low implementation accords contain more or less the same bipartite sub-graph structures and similar provisions are negotiated in both accord networks. Therefore, sub-graph frequencies in the binary negotiation networks do not explain differences in peace process success.

To incorporate implementation dynamics, we build a binary bipartite network for a specific year by connecting each accord with the provision that has changed implementation level when compared with the previous year. For instance, if the implementation score of an accord's provision has been 1 in year 1, 3 in year 2, and 3 in year 4 , then we include a connection between them in the networks built at year 1 and 2 , but not at year 3 or later. Given that the first three years after signing the accord are the most crucial in determining whether a peace process is going to be successful or conflict will resume, we show sub-graph frequencies for the first three years in Figure 5. Accordingly, the binary networks generated from implementation activity rather than the simple presence of provisions in peace accords show significant differences in sub-graph frequencies for all three years (KS test: $p<0.01$ ).

We proceed by detecting motifs, i.e., sub-graphs occurring at frequencies that are significantly higher than the frequencies found in the randomised ensemble described above.
We observe differences in motifs characteristic of high and low implementation success, as shown in Figure 6 In total, eight motifs are associated with low implementation networks; four out of these can also be found in high implementation networks. Motifs 10, 26, 32, and 34, typical among low implementation peace accords, belong to families of X-, W- and M-motifs that represent combinations of V- and A-motifs [28], [31]. V-Motifs account for the pairs of peace accords that implement the same provision, thereby quantifying a similarity between accords. Conversely, A-motifs account for the pairs of provisions implemented by the same peace accord. Xmotifs measure the co-occurrence of any two peace accords that implement the same couple of provisions, whereas Wand M-motifs enlarge the set of accords/provisions in $\mathrm{V}$ - and A-motifs, thereby describing higher-order correlations. These same classes of motifs have been identified in ecological and economic networks where they have been shown to provide meaningful insights into the structure of biotic interactions and roles of species in ecosystems [31] as well as in the early detection of structural changes indicative of impending financial crises in the World Trade Web (WTW) [28].

Network motifs therefore provide a high-level comparison between low and high implementation networks, but no further information about the identity of individual nodes in specific motifs. Moreover, they only focus on frequency and ignore the order of implementations. To address these lacks, in the next step we identify specific sequences of provision implementation activity characteristic of high and low implementation success. We believe that this yields substantial merit for peacebuilding practice and discuss thus in the following our implementation of a graph topological sorting algorithm for mining such sequences.

\section{B. Ordered Implementation Sequences}

To find critical paths or provision implementation sequences that are associated with high implementation success, we argue that one can use similarities between provisions in terms of the accords that implemented them. The basic idea is that for each implementation year, we define the similarity between provisions based on their implementability and assume that previously similarly successful provisions will facilitate overall successful implementation, if implemented concurrently again. Specifically, if two provisions have been implemented to the same extent by a similar set of accords, they could be tackled 


\section{IEEE/ACM International Conference on Advances in Social Networks Analysis and Mining}

concurrently because either their implementation required similar infrastructure or their preconditions were already met. This idea fits neatly into a broad formalism introduced to identify meta-groups in networks [32].

We develop Algorithm 1 by adapting the meta-group framework with respect to our key objectives: (i) Instead of chronologically, we order provisions by implementability as a basis for similarity; and (ii) We replace the set similarity measure (e.g., the Jaccard index) with a weighted similarity to account for the extent to which accords implement provisions. The adapted algorithm can then be formalised as follows: Given a set of provisions $P=\left\{p_{1}, p_{2}, \ldots, p_{t}\right\}$, we partition them by their normalised implementability score, $\pi_{1}, \pi_{2}, \ldots, \pi_{n}$ of $P$, one partition for each normalised implementability score $\hat{n}_{p}$. Each partition, $\pi_{i}$, is then a set of disjoint provisions. $\pi(p)$ denotes the index of the partition to which $p$ belongs, i.e., if $p \in \pi_{i}$ then $\pi(p)=i$. Given two provisions, $p$ and $p^{\prime}$, we define a similarity measure for them as:

$$
\operatorname{sim}\left(p, p^{\prime}\right)=\sum_{a=1}^{A}\left|m_{a p}-m_{a p^{\prime}}\right| .
$$

We say that the provisions are similar if $\operatorname{sim}\left(p, p^{\prime}\right) \geq \beta$, where $\beta$ is a threshold. A meta-group is then a sequence of provisions such that provisions are ordered by partition implementability

$$
i, j, 1 \leq i<j \leq t: \pi\left(p_{i}\right)<\pi\left(p_{j}\right)
$$

and consecutive provisions in the meta-group are similar

$$
i, 1 \leq i<t: \operatorname{sim}\left(p_{i}, p_{i+1}\right) \geq \beta .
$$

Building the meta-group this way produces a Directed Acyclic Graph (DAG) whose nodes are provisions and whose edges go from $p_{i}$ to $p_{j}$ if $\pi\left(p_{i}\right)<\pi\left(p_{j}\right)$ and $\operatorname{sim}\left(p_{i}, p_{j}\right) \geq \beta$. A topological sorting of this DAG enables studying the longest and heaviest paths, associated with the most persistent and most stable meta-groups, respectively.

\section{Algorithm 1: Meta-Group Mining $(t, \beta)$}

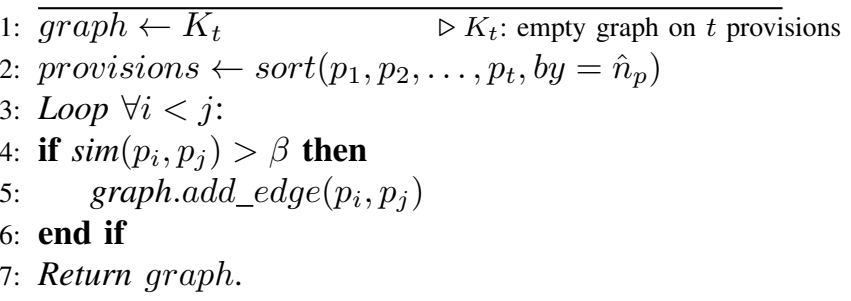

Using Algorithm 11, we create meta-groups for the $t=$ 10 provisions with highest implementability using different ranges of $\beta$ and compare implementation sequences between high and low implementation networks to investigate whether there exist differences in patterns that are associated with higher implementation success. Our results show different implementation sequences characteristic of high and low implementation success in the corresponding networks as shown in Figure 7. The sequences shown are representative for years 2 and 3 as well and provide thus a representative account

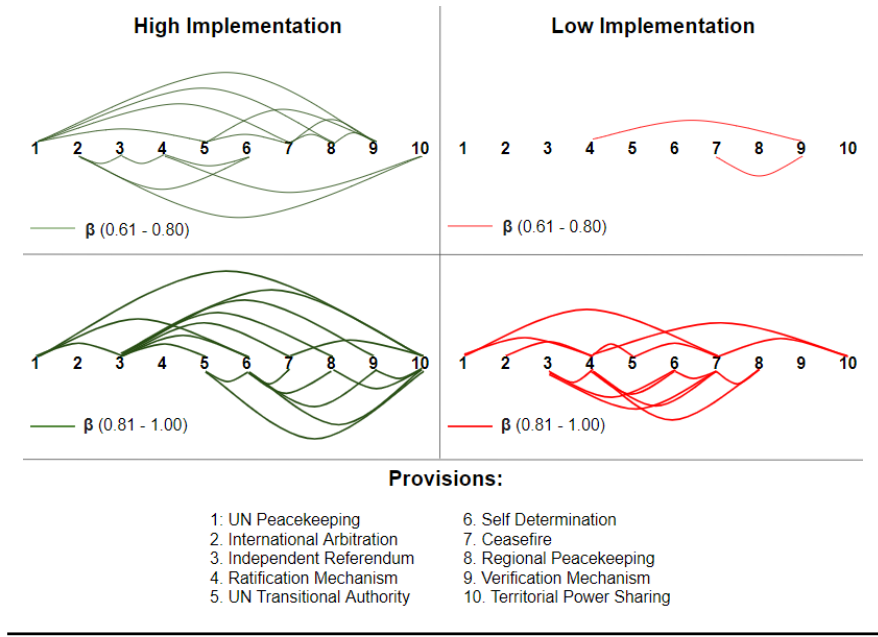

FIG. 7: Provision meta-groups for high and low implementation peace accords in their first implementation year. Provisions with higher implementability have higher precedence in the topologically sorted graphs than those with lower implementability. Implementability decreases from left to right; direction of arrows are omitted for clarity and in each case go from left to right.

of implementation sequences in the most critical years after signing an accord. Note that, despite the sparsity of the low implementation sequence at lower similarity thresholds, high implementation sequences are more persistent than low implementation sequences. The persistence of each implementation sequence can be easily measured by finding the longest path in the sequence. In the context of peacebuilding, the most persistent implementation sequence maximises the number of provisions implemented within the meta-group thereby maximising the aggregate implementation score which captures the overall success of a peace accord.

\section{CONCLUSION}

Peace research has historically been theory-rich and datapoor. Recent data collection efforts have provided a valuable world-wide data set, but analytical and computational tools to analyse it have been lagging. Specifically, it has not been investigated from a network perspective before. Given indication from within the peace research community for the importance of interdependencies between peace accords and their provisions [16], in this paper, we modelled the Peace Accords Matrix as a network, thereby providing a systematic characterisation of peace accord diversification, provision ubiquity, implementability, and nestedness. Furthermore, we identified statistically significant network patterns and implementation sequences indicative of high vs low implementation success. Our results show that differences in negotiated provisions do not explain subsequent implementation success. Instead, we detected four higher order motifs that are statistically significant only in low implementation networks. These are variations of X-, W-, and M-motifs, also observed in ecological and economic networks. Additionally, we found provision 


\section{IEEE/ACM International Conference on Advances in Social Networks Analysis and Mining}

sequences that are characteristic of high peace process implementation success.

We anticipate that the identified differences in motifs and meta-groups between high and low implementation networks can serve as early-warning indicators of unsuccessful implementation, allowing timely adjustments and making considerable differences for affected areas. Further research can build upon the graph topological features identified here to design machine learning models for early prediction of peace process success or failure. A different line of future work could track the long-term evolution of peacebuilding and make methodological contributions by developing aggregation methods that integrate yearly provision implementation sequences and establish which year-to-year sequences lead to high longterm success. These and similar efforts would continue to advance an area of study that has critical broad impacts and to which this paper has contributed knowledge on how to design better peace accord implementation plans that glean useful information from intrinsically interconnected peace processes.

\section{REFERENCES}

[1] J. Kreutz, "How and when armed conflicts end: Introducing the UCDP conflict termination dataset," Journal of Peace Research, vol. 47, no. 2, pp. 243-250, 2010.

[2] R. Licklider, "Peace time: Cease-fire agreements and the durability of peace by virginia page fortna," Political Science Quarterly, vol. 120, no. 1, pp. 149-151, 2005.

[3] C. Bell, "Peace agreements: Their nature and legal status," American Journal of International Law, pp. 373-412, 2006.

[4] M. Joshi, E. Melander, and J. Quinn, "Systemic peace, multiple terminations, and a trend towards long-term civil war reduction." International Studies Association Annual Conference, pp. 16-19, 2016.

[5] S. J. Stedman, D. S. Rothchild, D. Rothchild, and E. M. Cousens, Ending civil wars: The implementation of peace agreements. Lynne Rienner Publishers, 2002.

[6] C. T. Call and E. M. Cousens, "Ending wars and building peace: International responses to war-torn societies," International Studies Perspectives, vol. 9, no. 1, pp. 1-21, 2008. [Online]. Available: http://dx.doi.org/10.1111/j.1528-3585.2007.00313.x

[7] C. Hartzell, M. Hoddie, and D. Rothchild, "Stabilizing the peace after civil war:An investigation of some key variables," International Organization, vol. 55, no. 01, pp. 183-208, 2001.

[8] P. Doreian and A. Mrvar, "Structural balance and signed international relations," Journal of Social Structure, vol. 16, p. 1, 2015.

[9] E. M. Hafner-Burton, M. Kahler, and A. H. Montgomery, "Network analysis for international relations," International Organization, vol. 63, no. 3, pp. 559-592, 2009.

[10] D. A. Bekoe, "Toward a theory of peace agreement implementation: The case of Liberia," Journal of Asian and African Studies, vol. 38, no. 2-3, pp. 256-294, 2003.

[11] D. Bekoe, Implementing peace agreements: Lessons from Mozambique, Angola, and Liberia. Springer, 2008.

[12] M. Boltjes and K. (association), Implementing negotiated agreements: the real challenge to intrastate peace. TMC Asser Press The Hague, 2007.

[13] K. DeRouen Jr, M. J. Ferguson, S. Norton, Y. H. Park, J. Lea, and A. Streat-Bartlett, "Civil war peace agreement implementation and state capacity," Journal of Peace Research, vol. 47, no. 3, pp. 333-346, 2010.

[14] W. Maekawa, B. Arı, and T.-I. Gizelis, "UN involvement and civil war peace agreement implementation," Public Choice, vol. 178, no. 3-4, pp. 397-416, 2019.

[15] M. Joshi and J. M. Quinn, "Implementing the peace: The aggregate implementation of comprehensive peace agreements and peace duration after intrastate armed conflict," British Journal of Political Science, pp. $1-24,2015$.

[16] M. Joshi, E. Melander, and J. M. Quinn, "Sequencing the peace: How the order of peace agreement implementation can reduce the destabilizing effects of post-accord elections," Journal of Conflict Resolution, vol. 61, no. 1, pp. 4-28, 2017.

[17] J.-L. Guillaume and M. Latapy, "Bipartite structure of all complex networks," Information Processing Letters, vol. 90, no. 5, pp. 215-221, 2004.

[18] Y. Jiang, T. Xu, and D.-R. He, "A self-adaptive model of actorcollaboration network," International Journal of Modern Physics B, vol. 18 , no. 17n19, pp. 2604-2607, 2004.

[19] M. E. Newman, "Scientific collaboration networks. i. network construction and fundamental results," Physical Review E, vol. 64, no. 1, p. 016131, 2001.

[20] S. Saavedra, F. Reed-Tsochas, and B. Uzzi, "A simple model of bipartite cooperation for ecological and organizational networks," Nature, vol. 457, no. 7228, p. 463, 2009.

[21] C. F. Dormann, J. Fründ, N. Blüthgen, and B. Gruber, "Indices, graphs and null models: Analyzing bipartite ecological networks," The Open Ecology Journal, vol. 2, no. 1, 2009.

[22] R. MacArthur, "The theory of island biogeography," Monographs in Population Biology. Princeton University Press, Princeton, NJ, 1967.

[23] P. J. Darlington, Zoogeography. John Wiley: New York, 1957.

[24] S. Gualdi, G. Cimini, K. Primicerio, R. Di Clemente, and D. Challet, "Statistically validated network of portfolio overlaps and systemic risk," Scientific Reports, vol. 6, p. 39467, 2016.

[25] C. A. Hidalgo and R. Hausmann, "The building blocks of economic complexity," Proceedings of the National Academy of Sciences, vol. 106, no. 26, pp. 10 570-10 575, 2009.

[26] M. Cristelli, A. Gabrielli, A. Tacchella, G. Caldarelli, and L. Pietronero, "Measuring the intangibles: A metrics for the economic complexity of countries and products," PloS One, vol. 8, no. 8, p. e70726, 2013.

[27] A. Tacchella, M. Cristelli, G. Caldarelli, A. Gabrielli, and L. Pietronero, "A new metrics for countries' fitness and products' complexity," Scientific Reports, vol. 2, p. 723, 2012.

[28] F. Saracco, R. Di Clemente, A. Gabrielli, and T. Squartini, "Detecting early signs of the 2007-2008 crisis in the world trade," Scientific Reports, vol. 6, p. 30286, 2016.

[29] R. Milo, S. Shen-Orr, S. Itzkovitz, N. Kashtan, D. Chklovskii, and U. Alon, "Network motifs: Simple building blocks of complex networks," Science, vol. 298, no. 5594, pp. 824-827, 2002.

[30] J. Bascompte, P. Jordano, C. J. Melián, and J. M. Olesen, "The nested assembly of plant-animal mutualistic networks," Proceedings of the National Academy of Sciences, vol. 100, no. 16, pp. 9383-9387, 2003.

[31] B. I. Simmons, A. R. Cirtwill, N. J. Baker, H. S. Wauchope, L. V. Dicks, D. B. Stouffer, and W. J. Sutherland, "Motifs in bipartite ecological networks: Uncovering indirect interactions," Oikos, 2018.

[32] T. Y. Berger-Wolf and J. Saia, "A framework for analysis of dynamic social networks," in Proceedings of the 12th ACM SIGKDD International Conference on Knowledge Discovery and Data Mining. ACM, 2006, pp. 523-528.

[33] M. Joshi and J. Darby, "Introducing the Peace Accords Matrix (PAM): A database of comprehensive peace agreements and their implementation, 1989-2007," Peacebuilding, vol. 1, no. 2, pp. 256-274, 2013.

[34] M. Joshi, J. M. Quinn, and P. M. Regan, "Annualized implementation data on comprehensive intrastate peace accords, 1989-2012," Journal of Peace Research, vol. 52, no. 4, pp. 551-562, 2015.

[35] J. Darby and R. Mac Ginty, The management of peace processes. Springer, 2000.

[36] M. Almeida-Neto, P. Guimaraes, P. R. Guimaraes Jr, R. D. Loyola, and W. Ulrich, "A consistent metric for nestedness analysis in ecological systems: reconciling concept and measurement," Oikos, vol. 117, no. 8, pp. 1227-1239, 2008.

[37] B. I. Simmons, M. J. Sweering, M. Schillinger, L. V. Dicks, W. J. Sutherland, and R. Di Clemente, "bmotif: A package for motif analyses of bipartite networks," Methods in Ecology and Evolution, 2019.

[38] A. Gionis, H. Mannila, T. Mielikäinen, and P. Tsaparas, "Assessing data mining results via swap randomization," $A C M$ Transactions on Knowledge Discovery from Data (TKDD), vol. 1, no. 3, p. 14, 2007.

[39] K. A. Zweig and M. Kaufmann, "A systematic approach to the one-mode projection of bipartite graphs," Social Network Analysis and Mining, vol. 1, no. 3, pp. 187-218, 2011.

[40] E.-Á. Horvát and K. A. Zweig, "A fixed degree sequence model for the one-mode projection of multiplex bipartite graphs," Social Network Analysis and Mining, vol. 3, no. 4, pp. 1209-1224, 2013. 